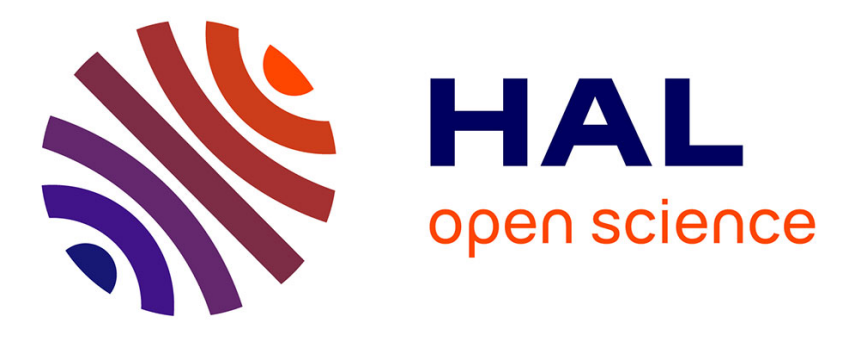

\title{
Tuning Adhesion at Metal/Oxide Interfaces by Surface Hydroxylation
}

Ha-Linh Thi Le, Remi Lazzari, Jacek Goniakowski, Remi Cavallotti, Stephane

Chenot, Claudine Noguera, Jacques Jupille, Alexey Koltsov, Jean-Michel

Mataigne

\section{To cite this version:}

Ha-Linh Thi Le, Remi Lazzari, Jacek Goniakowski, Remi Cavallotti, Stephane Chenot, et al.. Tuning Adhesion at Metal/Oxide Interfaces by Surface Hydroxylation. Journal of Physical Chemistry C, 2017, 121 (21), pp.11464-11471. 10.1021/acs.jpcc.7b02456 . hal-01520408

\section{HAL Id: hal-01520408 https: / hal.sorbonne-universite.fr/hal-01520408}

Submitted on 10 May 2017

HAL is a multi-disciplinary open access archive for the deposit and dissemination of scientific research documents, whether they are published or not. The documents may come from teaching and research institutions in France or abroad, or from public or private research centers.
L'archive ouverte pluridisciplinaire HAL, est destinée au dépôt et à la diffusion de documents scientifiques de niveau recherche, publiés ou non, émanant des établissements d'enseignement et de recherche français ou étrangers, des laboratoires publics ou privés. 


\title{
Tuning Adhesion at Metal/Oxide Interfaces by Surface Hydroxylation
}

\author{
Ha-Linh Thi Le, ${ }^{\dagger, \ddagger}$ Rémi Lazzari, ${ }^{*},+\ddagger$ Jacek Goniakowski, ${ }^{\dagger} \ddagger$ Rémi Cavallotti,,,,$+ \uparrow$ \\ Stéphane Chenot, ${ }^{\dagger, \ddagger}$ Claudine Noguera, ${ }^{\dagger, \ddagger}$ Jacques Jupille, ${ }^{\dagger, \ddagger}$ Alexey Koltsov, ${ }^{\natural}$ \\ and Jean-Michel Mataigne \\ $\dagger$ CNRS, UMR 7588, Institut des NanoSciences de Paris, F-75005 Paris, France \\ $\ddagger$ Sorbonne Universités, UPMC Univ Paris 06, UMR 7588, Institut des NanoSciences de \\ Paris, F-75005 Paris, France \\ -ArcelorMittal Maizières Research, voie Romaine, F-57280, Maizières-lès-Metz, France \\ E-mail: remi.lazzari@insp.jussieu.fr
}

\section{Abstract}

The control of adhesion at metal/oxide interfaces is of key importance in modern applications, whenever three-dimensional metal clusters or two-dimensional metal overlayers are to be synthesized on an oxide support. By focusing on the zinc/alumina system, we address here one of the long-standing issues in this context, which is the poor wetting of wide bandgap oxides by noble and post-transition metals. It has recently been recognized to have detrimental industrial consequences for the adhesion of anti-corrosive zinc coatings to new high strength steels grades. We have combined photoemission, thermal desorption and plasmonics with atomistic simulation to describe the energetics of zinc deposits on dry and hydroxylated $\alpha-\mathrm{Al}_{2} \mathrm{O}_{3}(0001)$ surfaces. Both experimental and computational results show that an activated reaction of the metal with the $\mathrm{OH}-$ covered surface, followed by hydrogen desorption, produces dispersed interfacial moieties involving both oxidized $\mathrm{Zn}$ species and undercoordinated oxygen ions, that lead to a significant improvement of adsorption/adhesion characteristics on the hydroxylated surface. In particular, the key role of interfacial undercoordinated anions, remnants of the hydroxylation layer, is highlighted for the first time, pointing to a general mechanism by which surface hydroxylation appears as a promising route towards a systematic improvement of wide band gap oxide wetting by metals.

\section{Introduction}

Metal-oxide interfaces have been intensively studied because of their scientific and commercial importance. The many applications in which they are involved (e.g. microelectronics, thermal or optical coatings, catalysis) require quite diverse metal growth modes depending on the desired properties. For example, the need for three-dimensional nanoparticles of defined shape and size for catalysts contrasts with the development of two-dimensional growth for functional coatings. Therefore, beyond the understanding of the mechanisms at work during the build-up of metal-oxide interfaces, ${ }^{1-6}$ there is a constant search for methods that can help to keep adhesion under control. One such means is surface hydroxylation. The often invoked ability of $\mathrm{OH}$ groups to increase the adhesion energy via a charge transfer with the metal adlayer $^{5,7,8}$ is of extreme relevance since hydroxylation is an ubiquitous source of active sites at most oxide surfaces. The issue has been intensively studied on the $\alpha-\mathrm{Al}_{2} \mathrm{O}_{3}(0001)$ surface 
which shows a propensity to be hydroxylated by dissociative adsorption of water. ${ }^{9-12}$

Interactions of $\mathrm{Cu},{ }^{13,14} \mathrm{Co},{ }^{7} \mathrm{Ti}$ and $\mathrm{Al}^{5}$ metals with hydroxylated alumina have been specifically studied and a formation of a fraction of oxidized metal monolayer upon interaction with surface hydroxyls has been reported. However, beyond the demonstrated strong interaction of the oxidized species qualified as anchors with the alumina substrate, little is known on its consequences for the interface adhesion and oxide wetting by the multilayer metal film. Indeed, the key issue for the cohesive metal/oxide cleavage is the capability of these strongly bonded interfacial species to chemically bind also with the subsequently deposited metal layers. As will be shown in our present study, it is directly linked to the presence of undercoordinated anions and to the degree of interface dehydrogenation.

We have considered $\mathrm{Zn}$ deposits on $\alpha$ $\mathrm{Al}_{2} \mathrm{O}_{3}(0001)$, which is a model system for the galvanization process of advanced high strength steels, subject to surface segregation of oxides of electro-positive strengthening elements, such as Al, Mn, or $\mathrm{Si}^{15-19}$ (see SI Section S1). Moreover, the Zn/alumina system has several advantages. Firstly, it displays a favorable large difference in binding energies between nonreactive and reactive metal adsorption, ${ }^{8,20,21}$ giving good conditions to discriminate the different underlying mechanisms. Then, preliminary results have suggested that, similarly to $\mathrm{Cu}$ and $\mathrm{Co}$, a fraction of a monolayer of strongly bound oxidized zinc species is formed on a purposely hydroxylated $\mathrm{Al}_{2} \mathrm{O}_{3}(0001)$ surface. ${ }^{8,20,21}$ Finally, the domain of such strong $\mathrm{Zn}$ adsorption is expected to cover a wider range of oxygen/hydrogen conditions than for other metals. $^{21}$

The present work combines experimental techniques, namely Surface Differential Reflectivity Spectroscopy (SDRS) to determine the growth mode and the adhesion energies, Temperature Programmed Desorption (TPD) to determine adsorption energies, X-ray Photoemission Spectroscopy (XPS) to analyze chemical states and $a b$ initio atomistic simulations. Thanks to a comparison between $\mathrm{Zn}$ adsorp- tion/adhesion on a dry and on an hydroxylated alumina surface, our results highlight the conditions required to transform an interfacial cleavage into a cohesive one. They reveal that dispersed interfacial zinc oxide moieties formed by the substitution of the hydroxyl protons by Zn strongly bind to both the alumina substrate and the zinc adlayers that are further deposited upon the growth of the film. This conclusion is substantiated by chemical characterization of interfacial species, measurements and calculations of both adsorption and adhesion energies, observation of hydrogen desorption and analysis of interfacial charge transfers. It sketches a general mechanism by which surface hydroxylation opens a promising route towards a systematic improvement of wetting.

\section{Methods}

Experiments have been carried out in a vacuum set-up (base pressure of $5.10^{-9} \mathrm{~Pa}$ ) involving a load-lock system, a preparation chamber and a main chamber. ${ }^{22}$ In the latter, samples were analyzed by XPS with a Mg K $\alpha$ excitation source and Low Energy Electron Diffraction (LEED). The preparation chamber was equipped with dedicated manipulators on which samples could be cooled down to $100 \mathrm{~K}$ by circulating liquid nitrogen and annealed up to $1500 \mathrm{~K}$. An electron bombardement furnace was used to clean the $\alpha-\mathrm{Al}_{2} \mathrm{O}_{3}(0001)$ substrates by repeated annealing at $1200 \mathrm{~K}$ under an oxygen partial pressure of $5.10^{-4} \mathrm{~Pa}$ until they show carbon-free XPS spectra and sharp $(1 \times 1)$ LEED patterns (SI Section S2.5, Figure S7).

Hydroxylated $(1 \times 1)$ alumina surface were prepared on purpose via adsorption-desorption of thick ice layers formed by exposure to water vapor at $100 \mathrm{~K} .^{5,10}$ The maximum obtained $\mathrm{OH}$ coverage is $9.10^{14} \mathrm{OH} \cdot \mathrm{cm}^{-25,10,23}$ as estimated from the $\mathrm{O}$ 1s core level analysis, i.e. about $2 / 3$ of ML or one dissociated water molecule per unit cell, in close agreement with results of direct exposure to 1 mbar of water vapor. ${ }^{10,11}$ Reconstructed $\alpha-\mathrm{Al}_{2} \mathrm{O}_{3}(0001)$ $(\sqrt{31} \times \sqrt{31}) \mathrm{R} \pm 9^{\circ 24}$ surfaces were prepared 
by high temperature annealing above $1500 \mathrm{~K}$ in vacuum to serve as an $\mathrm{OH}$-free alumina surface. Metallic zinc was deposited at a pressure in the high $1.10^{-8} \mathrm{~Pa}$ on surfaces held at $100 \mathrm{~K}$ to obtain a sizeable condensation coefficient. ${ }^{20,25}$ Deposition rates ranged between $0.17-0.34 \mathrm{ML} / \mathrm{min}$ as calibrated by a quartz microbalance. A continuous thin film model was also used to estimate film thickness through ratio of zinc and alumina photoemission peak area after correction of ionization cross section and spectrometer transmission function using tabulated mean free paths in bulk alumina and zinc (see SI Section S2.4). The growth of Zn films was analyzed in situ by SDRS which allows to estimate wetting angle (and adhesion energy) by fitting SDRS spectra with suitable dielectric models ${ }^{22,26-31}$ (SI, Section S2.1). Once the deposition was completed, the desorption energy of the film $E_{\text {des }}$ was determined by TPD thanks to a differentially pumped mass spectrometer. Zn desorption has been analyzed in the framework of the so-called leading edge analysis $^{32}$ which is applied to the onset of the thermal desorption spectra where changes in temperature and coverage are small enough to assume constant desorption parameters (SI, Section S2.2 and Figure S3).

In the absence of sizeable zinc core level shifts upon oxidation, ${ }^{33,34}$ the chemical state of $\mathrm{Zn}$, was determined through the $\mathrm{Zn} \quad \mathrm{L}_{3} \mathrm{M}_{45} \mathrm{M}_{45}$ Auger line probed in XPS. Fingerprint spectra corresponding to metallic zinc and zinc oxide are presented in supporting information (Section S2.3, Figures S5-S6).

Calculations were performed within the Density Functional Theory (DFT), implemented in VASP (Vienna ab initio simulation package). ${ }^{35,36}$ The interaction of valence electrons with ionic cores was described within the projector augmented wave (PAW) method, ${ }^{37,38}$ and the Kohn-Sham orbitals were developed on a plane-wave basis set with a cutoff energy of $400 \mathrm{eV}$. The dispersion-corrected GGA (optB88-vdW) $)^{39-41}$ exchange-correlation functional was systematically used to improve the description of adhesion characteristics at weakly interacting metal/alumina interfaces, such as between $\mathrm{Zn}$ and the non-polar $\mathrm{Al}-$ terminated (0001) surface. ${ }^{8}$ The above settings assure a satisfactory agreement between calculated and experimental characteristics of bulk $\mathrm{Al}_{2} \mathrm{O}_{3}, \mathrm{ZnO}$ and $\mathrm{Zn} .{ }^{42}$

We have systematically considered the most stable stoichiometric Al-terminated alumina surface. The alumina substrate was represented by a slab composed of three $-\mathrm{Al} / 3 \mathrm{O} / \mathrm{Al}$ - layers, with equivalent adsorbates/interfaces at both terminations. The fully hydrated alumina surface involves one water molecule per surface unit cell. As mentioned above, this corresponds exactly to the maximum coverage which is experimentally observed. Adsorption in the limit of isolated $\mathrm{Zn}$ adatoms was approximated by a single $\mathrm{Zn}$ adsorbate per $(1 \times 1)$ alumina surface unit cell $(1 / 3 \mathrm{ML})$. This corresponds to Zn-Zn distances of about $4.7 \AA$, considerably larger than the interatomic distances in bulk Zn. The adsorption energy was evaluated directly from total energy differences: $E_{a d s}=-\left(E_{\text {slab }+Z n}-E_{\text {slab }}-E_{Z n}\right) / 2$. Free atom reference $E_{Z n}$ was used, such that the adsorption energy directly provides information on the bonding strength between the metal adatom and the oxide surface. The energy barrier between two adsorption configurations was evaluated with 5-point climbing image nudged elastic band method. ${ }^{43}$

The $\mathrm{Al}_{2} \mathrm{O}_{3}(0001)-(1 \times 1) \quad \| \mathrm{Zn}(0001)-$ $(\sqrt{3} \times \sqrt{3}) \mathrm{R} 30^{\circ}$ coincidence cell used in all interface calculations provides a particularly small mismatch between the two lattices ( $\leq$ $3 \%)$ and produces numerically tractable supercells. Slabs of seven $\mathrm{Zn}(0001)$ layers were used to represent the zinc deposit. The adhesion strength at an A/B interface was estimated from the separation energy defined as $E_{\text {sep }}=-\left(E_{A / B}-E_{A}-E_{B}\right) / 2 S$, where $E_{A / B}$, $E_{A}$, and $E_{B}$ are the total energies of the $\mathrm{A} / \mathrm{B}$ heterostructure and separated A and B systems, respectively. Factor 2 accounts for the two equivalent $\mathrm{A} / \mathrm{B}$ interfaces in each periodic unit cell and $\mathrm{S}$ is the interface area.

The in-plane lattice parameters of the heterostructures were fixed to those calculated for bulk alumina and the positions of all atoms were optimized until all components 
of the residual forces were smaller than $0.01 \mathrm{eV} / \AA$. In all calculations, a $\Gamma$-centered $8 \times 8 \times 1$ Monkhorst Pack grid for k-point sampling of the Brillouin zone was employed. Ionic charges were estimated within the partition scheme proposed by Bader ${ }^{44,45}$ and atomic configurations were plotted with VESTA. ${ }^{46}$

\section{Experimental results}

Zn films were grown by vapor deposition at $100 \mathrm{~K}$ on either hydroxylated $\alpha-\mathrm{Al}_{2} \mathrm{O}_{3}(0001)$ $(1 \times 1)$ surface or on reconstructed $\alpha$ $\mathrm{Al}_{2} \mathrm{O}_{3}(0001)-(\sqrt{31} \times \sqrt{31}) \mathrm{R} \pm 9^{\circ 24}$ which are referred to as $\mathrm{OH}$-covered and $\mathrm{OH}$-free surfaces in the following (see Section 2). The latter was used as a reference of non-hydroxylated surface since the existence of an hydroxyl-free $(1 \times 1)$ surface is questionable. ${ }^{5,47}$ On OH-covered surfaces, a maximum of about $2 / 3$ of monolayer (ML) or one dissociated water molecule per unit cell could be reached, consistently with the predicted stability of the non-polar alumina termination around room temperature and at low water vapor pressure. ${ }^{48}$ The monolayer (ML) as used hereafter is defined as $1.5210^{15}$ atoms.cm ${ }^{-2}$ corresponding to three oxygen atoms per unit cell in the $\alpha-\mathrm{Al}_{2} \mathrm{O}_{3}(0001)$ structure. Experimental conditions have been described in Section 2 and the techniques are detailed in Supporting Information (SI, Section 2).

SDRS spectra recorded in situ during the growth of Zn films on OH-free and hydroxylated alumina surfaces are dominated by a band around $3.2 \mathrm{eV}$ (SI, Figure S1) which lies within the high-energy tail of the Zn interband transitions. ${ }^{22}$ The comparison with the simulated response of a continuous two-dimensional film evidences a Volmer-Weber growth mode (SI, Figure S2). Dielectric modelling of the optical response with clusters represented by truncated spheres ${ }^{22,26-31}$ gives an average contact angle $\theta_{c}$ of $65^{\circ}$ from which the adhesion energy can be estimated by means of the Young-Dupré formula $E_{a d h}=\gamma_{Z n}\left(1+\cos \theta_{c}\right)$ with zinc surface energy of $\gamma_{Z n}=0.54 \mathrm{J.m}^{-2}$ as determined theoretically herein. This latter amounts to $E_{a d h}=0.75 \pm 0.1{\mathrm{~J} . \mathrm{m}^{-2}}^{-}$

Thermal desorptions of $\mathrm{Zn}$ and $\mathrm{H}_{2}$ from $\mathrm{Zn} / \mathrm{OH}$-free (Figure 1a) and Zn/OH-covered (Figure 1b) alumina were followed. The Polyani-Wigner analysis of the $\mathrm{Zn}$ peak lineshape (SI, Figure S3) and its shift with coverage (Figure 1c) evidence a fractional order of desorption as expected for supported clusters. ${ }^{49}$ Reproducible measurements and the comparison of both surfaces showed that hydrogen desorbing from $\mathrm{Zn} / \mathrm{OH}$-free surfaces (Figure 1a) is not intrinsic to the sample. Indeed, the unavoidable $\mathrm{H}_{2}$ desorption peak which systematically parallels that of $\mathrm{Zn}$ and the broad $\mathrm{H}_{2}$ feature seen around $850 \mathrm{~K}$ are assigned to a reaction of the desorbed metallic $\mathrm{Zn}$ on the mass spectrometer walls and to the annealing of the sample holder, respectively. From a photoemission point of view (SI Section S2.3), the $\mathrm{L}_{3} \mathrm{M}_{45} \mathrm{M}_{45}$ Auger lineshape demonstrates that $\mathrm{Zn}$ deposited on $\mathrm{OH}$-free surfaces remains metallic upon annealing, even at $505 \mathrm{~K}$ (Figure 2a), well beyond the desorption maximum (Figure 1a), at a point where the Zn coverage is estimated to 0.06 ML. The expected spectroscopic fingerprint of oxidized $\mathrm{Zn}$ on the lower kinetic energy side of $\mathrm{Zn} \mathrm{L}_{3} \mathrm{M}_{45} \mathrm{M}_{45}$ Auger line seen on hydroxylated surface at $505 \mathrm{~K}$ (Figure $2 \mathrm{~b}$ ) is negligible on $\mathrm{OH}$-free substrate (Figure $2 \mathrm{a}$ ), which supports the above assumption that the $\mathrm{H}_{2}$ desorption seen in Figure 1a does not come from the alumina surface. The desorption energy of $\mathrm{Zn}$ from $\mathrm{OH}$-free alumina amounts to $E_{\text {des }}=0.9 \pm 0.1 \mathrm{eV} /$ atom.

Compared to Figure 1a, two main extra characteristics are observed on $\mathrm{H}_{2}$ desorption spectra from $\mathrm{Zn} / \mathrm{OH}$-covered alumina (Figure $1 \mathrm{~b}$ ). Firstly, $\mathrm{H}_{2}$ and $\mathrm{Zn}$ desorption onsets do not coincide anymore and secondy, the dominant $\mathrm{H}_{2}$ desorption occurs at temperatures higher than that at which the zinc ends desorbing, which suggests a complex $\mathrm{Zn}-\mathrm{OH}$ reaction. In line with this, the kink observed at the onset of the Zn TPD spectra between 400 and $440 \mathrm{~K}$ (shown by an arrow in Figure 1c) corresponds to a shift of the desorption line towards higher temperature, i.e. to an increase in $E_{\text {des }}$. As seen from an accurate leading 
Table 1: Estimates of desorption energies $E_{\text {des }}$ and temperatures $T_{\text {des }}$ of $\mathrm{Zn} / \alpha$ $\mathrm{Al}_{2} \mathrm{O}_{3}(0001)$ determined via thermal desorption (TPD) measurements by either leading edge $(\star)$ or Redhead's $(\star \star)$ analysis. Experimental values are averaged over all measurements. Error bars correspond to standard deviations over several experiments.

\begin{tabular}{l|c|c|c}
\multirow{2}{*}{} & Zn/OH-free alumina & \multicolumn{2}{|c}{ Zn/OH-covered alumina } \\
\cline { 2 - 4 } & metallic Zn & metallic Zn/ oxidized Zn & oxidized Zn \\
\hline$E_{\text {des }}(\mathrm{eV} /$ atom $)$ & $0.9 \pm 0.1^{\star}$ & $1.15 \pm 0.05^{\star}$ & $3.9^{\star \star}$ \\
$T_{\text {des }}(\mathrm{K})$ & $>400$ & $>430$ & $\sim 1380$
\end{tabular}

edge desorption analysis (SI Section S2.2 and Figure S3), the value of Zn desorption energy (Table 1) measured on the $\mathrm{OH}$-covered surface $\left(E_{d e s}=1.15 \pm 0.05 \mathrm{eV} /\right.$ atom $)$ is higher than that recorded on the $\mathrm{OH}$-free alumina $\left(E_{\text {des }}=0.9 \pm 0.05 \mathrm{eV} /\right.$ atom $)$. The reproducible difference of desorption energies attested by the small values of the standard deviation (SI, Figure S4) provides an additional evidence for the occurrence of a chemical change within the $\mathrm{Zn} / \mathrm{OH}$-alumina film during the desorption process. The assumption is further substantiated by the direct observation of the oxidation state of $\mathrm{Zn}$. Whatever the surface, $\mathrm{Zn}$ deposited at $100 \mathrm{~K}$ is always metallic, as shown by the perfect similarity of the Auger line (Figure 2) with reference spectra (SI, Figure S6), even down to coverages of the order of $1 \%$ of ML. In contrast with the total absence of oxidized zinc after deposition of zinc at $100 \mathrm{~K}$ on hydroxylated surfaces, the $\mathrm{Zn} \mathrm{L}_{3} \mathrm{M}_{45} \mathrm{M}_{45}$ lineshape undergoes a dramatic evolution upon annealing (Figure 2b). An oxide component appears in the $\mathrm{Zn}$ Auger line at $425 \mathrm{~K}$, a temperature close to that at which the kink appears in the $\mathrm{Zn}$ desorption spectra (Figure 1c), until the broad profile associated to $\mathrm{Zn}^{2+}$ in pure $\mathrm{ZnO}^{50,51}$ (see SI, Figures S5-S6) is obtained at $505 \mathrm{~K}$. The ionization of $\mathrm{Zn}$ mainly occurs at the onset of the desorption of $\mathrm{Zn}$ which is peaking between 480 and $525 \mathrm{~K}$. Above $505 \mathrm{~K}$, the $\mathrm{Zn}$ Auger lineshape and intensity are stable (Figure 2b). The oxidized zinc desorbs beyond $1380 \mathrm{~K}$ under vacuum, which corresponds to strongly bonded species having a desorption energy of $E_{\text {des }} \simeq 3.9 \mathrm{eV}$, as given by the Redhead's formula ${ }^{52}$ with a pre-exponential factor of $1.10^{13}$ (Table 1, SI Section S2.2).

The persistence of metallic Zn upon anneal- ing the $\mathrm{Zn} / \mathrm{OH}$-free alumina discards any role of either residual gases or impurities in the formation of oxidized $\mathrm{Zn}$ on the hydroxylated alumina. This proves instead that $\mathrm{Zn}$ reacts with the surface $\mathrm{OH}$. The maximum amount of oxidized Zn that has been estimated from photoemission was $5.10^{14}$ atoms.cm ${ }^{-2}$, which corresponds to about one $\mathrm{Zn}$ per $\mathrm{Al}_{2} \mathrm{O}_{3}$ surface unit cell or to a $\mathrm{Zn}^{2+}: \mathrm{OH}$ ratio close to $1: 2$. Therefore, the $\mathrm{Zn}$ oxidation reaction involves nearly all the surface $\mathrm{OH}$ and is limited by the $\mathrm{OH}$ coverage.

Increase in desorption energy of $\mathrm{Zn}$ on hydroxylated alumina (Table 1) likely corresponds to an enhancement in the $\mathrm{Zn} /$ alumina adhesion energy. However, as a property of individual atoms, desorption energy may not show the same trend as adhesion which describes a collective behavior. To further explore this issue and the mechanism through which adsorption and adhesion enhancements occur, the interfaces of isolated $\mathrm{Zn}$ atoms and $\mathrm{Zn}$ films with dry and hydroxylated alumina surfaces were considered via Density Functional Theory (DFT) approaches (see Section 2).

\section{Theoretical results}

Guided by the experimental evidence, numerical simulations were successively performed for individual $\mathrm{Zn}$ atoms and for constituted Zn deposits on dry and hydroxylated non-polar alumina surfaces. Figure 3a shows the considered adsorption configurations of $\mathrm{Zn}$ adatoms under various environment conditions: adsorption on the dry surface (configuration $\mathrm{A}_{1}$ ), on the fully hydroxylated surface (configuration $\mathrm{A}_{2}$ ), and 

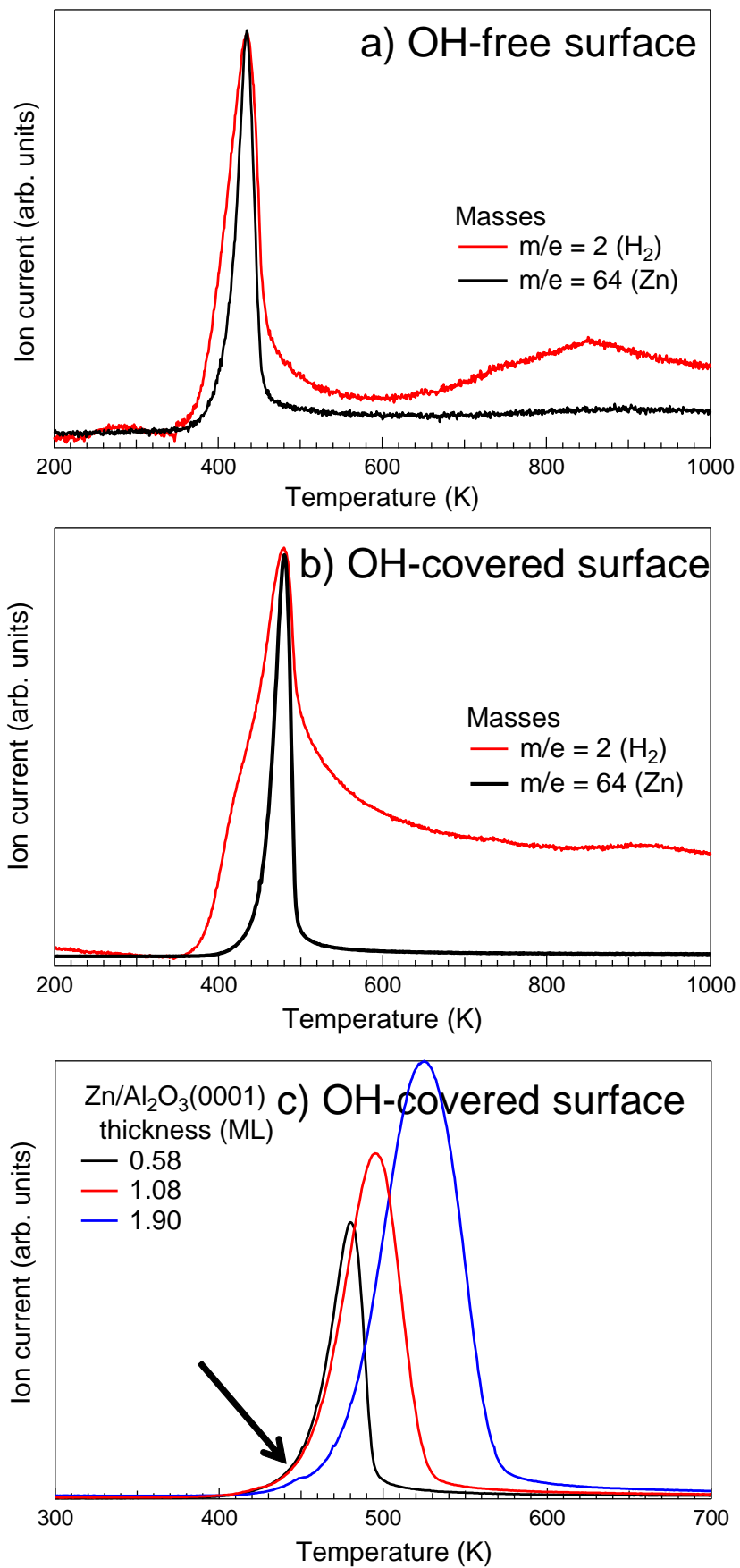

Figure 1: $\mathrm{H}_{2}$ and $\mathrm{Zn}$ thermal desorption spectra from a) Zn/OH-free (0.9 ML thick Zn film) and b) Zn/OH-covered (0.4 ML thick Zn film) alumina surfaces. c) Zinc TPD spectra from $\mathrm{Zn} / \mathrm{OH}$-covered alumina for three different coverage; note the reproducible kink shown by an arrow for the highest coverage (see text). The heating rate is $0.5 \mathrm{~K} . \mathrm{s}^{-1}$.
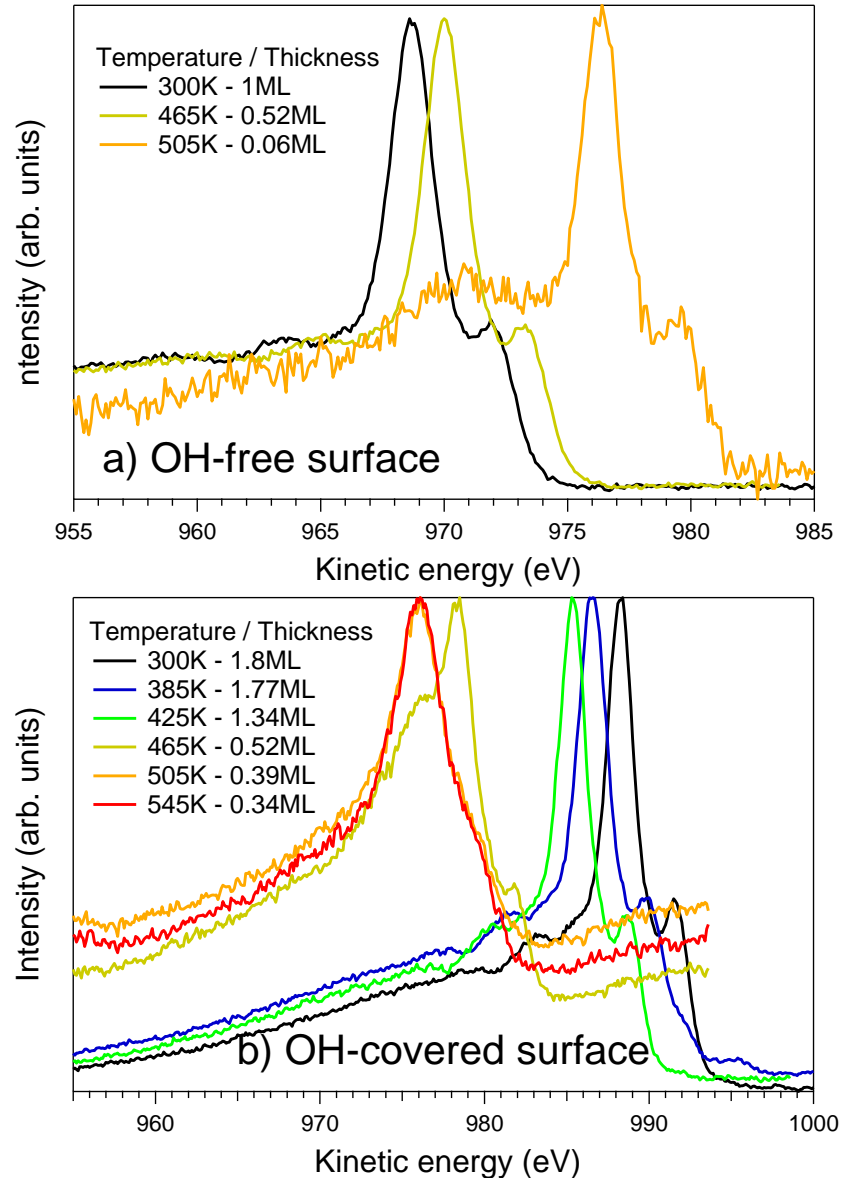

Figure 2: $\mathrm{Zn} \mathrm{L}_{3} \mathrm{M}_{45} \mathrm{M}_{45}$ Auger spectra: a) 1.0 ML thick Zn film on $\mathrm{OH}$-free alumina surface annealed at increasing temperature (shown in figure): zinc remains metallic even at $505 \mathrm{~K}$ (see text); b) 1.8 ML thick Zn film on OHcovered alumina surface; note the change of lineshape from metallic Zn (300 to $425 \mathrm{~K}$ ) to oxidized Zn (505 and $545 \mathrm{~K}$ ) via a metal/oxide mixture (465 K). Spectra have been normalized to the maximum of intensity and not corrected from charge effects due to the insulating character of the alumina substrate. 
on hydroxylated surface in H-lean conditions in which one (configuration $\mathrm{A}_{3}$ ) or two (configuration $\mathrm{A}_{4}$ ) hydrogen atoms per surface unit cell are absent. Table 2 gives the corresponding adsorption energies $E_{a d s}$ per Zn atom.

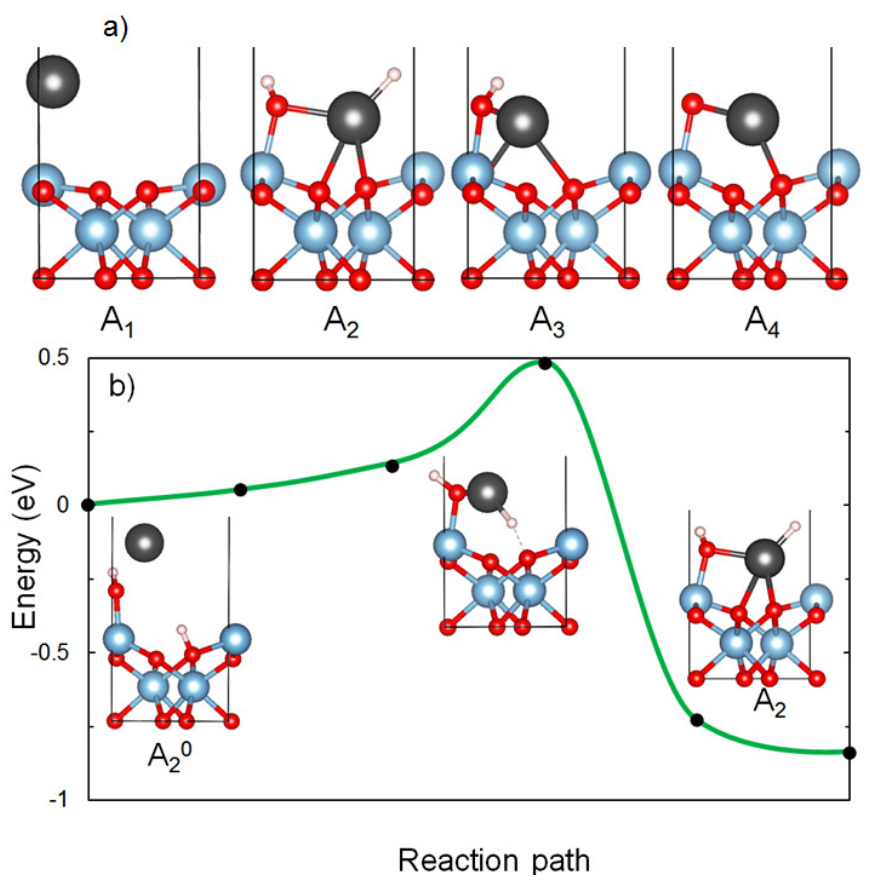

Figure 3: a) Adsorption configurations of $\mathrm{Zn}$ adatoms on a dry $\left(\mathrm{A}_{1}\right)$ and an hydroxylated $\left(\mathrm{A}_{2}-\mathrm{A}_{4}\right) \mathrm{Al}_{2} \mathrm{O}_{3}(0001)-(1 \times 1)$ surface under various environment conditions. b) Energy barrier between weakly $\left(\mathrm{A}_{2}^{0}\right)$ and strongly $\left(\mathrm{A}_{2}\right)$ adsorbed $\mathrm{Zn}$ configurations on the hydroxylated alumina surface (see text). Red, blue and grey balls stand for oxygen, aluminum and hydrogen atoms respectively.

Adsorption energies are found to increase along the series. On the dry surface (configuration $\left.\mathrm{A}_{1}\right), E_{\text {ads }}$ is very weak, consistently with the post-transition character of $\mathrm{Zn}$ and its formally zero oxidation state. It is associated to a very weak electron transfer towards the alumina surface and a large adsorbate-surface distance $(>3 \AA) . E_{a d s}$ is substantially enhanced on the hydroxylated surface (configuration $\mathrm{A}_{2}$ ), upon an exchange of $\mathrm{Zn}$ with the hydrogen directly bound to a surface oxygen. This process, which can be schematized as $\mathrm{OH}^{-}+\mathrm{Zn}$ $\longrightarrow \mathrm{O}^{2-}+(\mathrm{ZnH})^{+}$, results in an ionization of the adsorbed $\mathrm{Zn}$ to the formal $2+$ oxidation state (Bader charge $Q_{Z n}=0.86 \mathrm{e}$ ) and in a
Table 2: Adsorption and adhesion energies of $\mathrm{Zn}$ on the $\mathrm{Al}_{2} \mathrm{O}_{3}(0001)$ surface, associated to the configurations $\mathrm{A}, \mathrm{B}, \mathrm{C}$ represented in Figures 3 and 4 . Corresponding Bader charges of the interfacial Zn atom $Q_{Z n}^{a t}$ and of the zinc deposit $Q_{Z n}^{d e}$ are also given. For reference $Q_{Z n}=1.17$ $e$ in bulk $\mathrm{ZnO}$.

\begin{tabular}{lcccc} 
Zn adsorption & $\mathrm{A}_{1}$ & $\mathrm{~A}_{2}$ & $\mathrm{~A}_{3}$ & $\mathrm{~A}_{4}$ \\
\hline$E_{a d s}(\mathrm{eV} / \mathrm{Zn})$ & 0.31 & 1.07 & 2.07 & 5.14 \\
$Q_{Z n}^{a t}(\mathrm{e})$ & 0.16 & 0.86 & 0.70 & 1.01
\end{tabular}

\begin{tabular}{lcccc} 
Zn adhesion & $\mathrm{B}_{1}$ & $\mathrm{~B}_{2}$ & $\mathrm{~B}_{3}$ & $\mathrm{~B}_{4}$ \\
\hline$E_{\text {adh }}\left(\mathrm{i}_{2}\right)\left(\mathrm{J}_{\mathrm{m}}-2\right)$ & 1.07 & 0.29 & 1.03 & 1.63 \\
$E_{\text {adh }}\left(\mathrm{i}_{1}\right)\left(\mathrm{J} \cdot \mathrm{m}^{-2}\right)$ & 0.76 & 1.97 & 1.43 & 1.71 \\
$Q_{Z n}^{a t}(\mathrm{e})$ & 0.37 & 0.96 & 0.63 & 0.72 \\
$Q_{Z n}^{d e}(\mathrm{e})$ & -0.33 & 0.04 & 0.12 & 0.53
\end{tabular}

\begin{tabular}{lcccc} 
Zn adhesion & $\mathrm{C}_{1}$ & $\mathrm{C}_{2}$ & $\mathrm{C}_{3}$ & $\mathrm{C}_{4}$ \\
\hline$E_{\text {adh }}\left(\mathrm{i}_{2}\right)\left(\mathrm{J} . \mathrm{m}^{-2}\right)$ & 1.08 & 0.23 & 1.59 & 2.54 \\
$E_{\text {adh }}\left(\mathrm{i}_{1}\right)\left(\mathrm{J} \cdot \mathrm{m}^{-2}\right)$ & 0.65 & 1.15 & 1.11 & 1.80 \\
$Q_{Z n}^{m e}(\mathrm{e})$ & 0.09 & 0.05 & 0.49 & 1.26 \\
\hline
\end{tabular}

negative charging of the hydrogen atom (Bader charge $Q_{H}=-0.34 e$, to be compared to its average Bader charge in surface hydroxyl groups $\left.\begin{array}{lll}Q_{H} & 0.7 & e\end{array}\right)$. The $\mathrm{Zn}$ adatom forms two bonds $\left(\mathrm{d}_{O-Z n}<2.5 \AA\right)$ with the surface oxygens and one with the oxygen from the $\mathrm{OH}^{-}$group. We stress that, due to the passivating character of the surface hydroxyls, the zinc ionization is not spontaneous, but requires overcoming an energy barrier of about $0.5 \mathrm{eV}$ (Figure $3 \mathrm{~b}$ ) with respect to an initial, weakly bound configuration $\mathrm{A}_{2}^{0}\left(E_{\text {ads }}=0.23 \mathrm{eV}\right)$. Finally, in the hydrogendeficient configurations (configurations $\mathrm{A}_{3}$ and $A_{4}$ ), the adsorption energies go on increasing as more $\mathrm{H}$ atoms are removed. This is principally due to the cost of the charge excess accommodation by the alumina surface upon desorption of neutral zinc atoms.

Figure 4 shows two alternative series of configurations $\left(\mathrm{B}_{1}-\mathrm{B}_{4}\right.$ and $\left.\mathrm{C}_{1}-\mathrm{C}_{4}\right)$ for constituted $\mathrm{Zn} / \mathrm{Al}_{2} \mathrm{O}_{3}(0001)$ interfaces under conditions analogous to those of configurations $A_{1}$ to $\mathrm{A}_{4}$. In the series $\mathrm{B}$ the initially adsorbed $\mathrm{Zn}$ adatom is explicitly included, whereas it is absent in the series $\mathrm{C}$. The corresponding adhesion 
energies at the alumina termination [interface $\left(\mathrm{i}_{1}\right)$ ] and at the $\mathrm{Zn}$ interface [interface $\left(\mathrm{i}_{2}\right)$ ] are given in Table 2. Despite their different interface structures, the two series of configurations give fully consistent results.

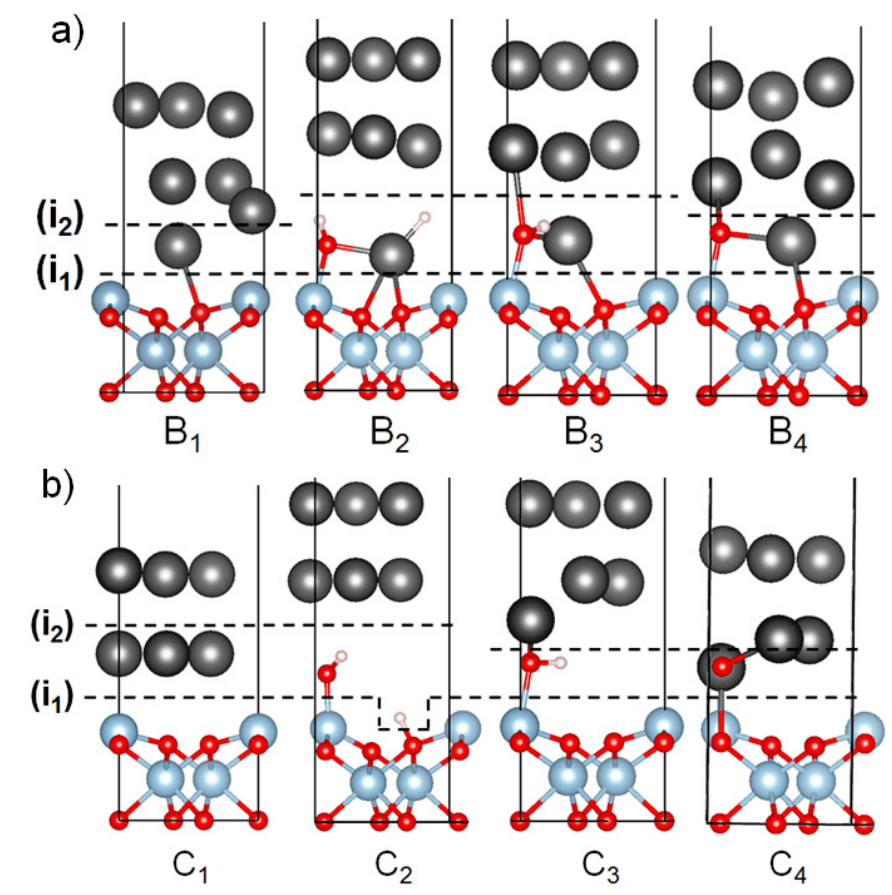

Figure 4: Two alternative series of configurations of a $\mathrm{Zn}$ deposit on a dry $\left(\mathrm{B}_{1}\right.$ or $\left.\left.\mathrm{C}_{1}\right)\right)$ and an hydroxylated $\left(\mathrm{B}_{2}-\mathrm{B}_{4}\right.$ or $\left.\mathrm{C}_{2}-\mathrm{C}_{4}\right) \mathrm{Al}_{2} \mathrm{O}_{3}$ (0001)$(1 \times 1)$ surface under various environment conditions (see text).

Both on the dry and on the fully hydroxylated surface (configurations $\mathrm{B}_{1} / \mathrm{C}_{1}$ and $\mathrm{B}_{2} / \mathrm{C}_{2}$ ), a weak interface is formed, either at $\left(i_{1}\right)$ when the surface is dry, or at $\left(\mathrm{i}_{2}\right)$ when it is hydroxylated. These adhesion energies are weaker than the cleavage energy calculated for bulk Zn (1.08 $\mathrm{J.m}^{-2}$ ), representative for the strength of the zinc film itself. We note that $E_{a d h}\left(\mathrm{i}_{1}\right)$ on the dry surface (configurations $\mathrm{B}_{1} / \mathrm{C}_{1}$ ) is only slightly stronger compared to the case of isolated adatoms (configuration $\mathrm{A}_{1}$ ). On the hydroxylated surface (configurations $\mathrm{B}_{2} / \mathrm{C}_{2}$ ), a substantial adhesion is obtained at $\left(\mathrm{i}_{1}\right)$ interface but the interaction with the $\mathrm{Zn}$ overlayer $\left(\mathrm{i}_{2}\right)$ is in both cases too weak to provide a sufficiently good adhesion.

In contrast, under hydrogen-lean conditions (configurations $\mathrm{B}_{3} / \mathrm{C}_{3}$ and $\mathrm{B}_{4} / \mathrm{C}_{4}$ ), much better global adhesion performances are obtained, simultaneously at $\left(i_{1}\right)$ and $\left(i_{2}\right)$ interfaces. The most striking effect is obtained in the absence of hydrogen (configuration $\mathrm{B}_{4}$ ), where the interfacial $\mathrm{ZnO}$ species not only form strong Al$\mathrm{O}$ and $\mathrm{Zn}-\mathrm{O}$ bonds with the alumina surface, but also Zn-O bonds with the top Zn layers, characterized by a sizeable charge transfer and a reinforcement of $\mathrm{Zn}-\mathrm{Zn}$ interaction in the interface vicinity. Interestingly, a very similar adhesion improvement under H-lean conditions is obtained with an alternative interfacial configuration $\left(\mathrm{C}_{4}\right)$, in which the number of interfacial bonds and charge distribution at the interface are similar to those in the configuration $\mathrm{B}_{4}$. This points to the generality of the calculated trends in interfacial energetics beyond a particular interface model. The ensemble of computational results highlights the key role of a dense network of under-coordinated interfacial anions remnants of surface hydroxyls in the formation of strong $\mathrm{O}-\mathrm{Al}$ and $\mathrm{O}-\mathrm{Zn}$ bonds at the interface, which enables the transformation of an interfacial cleavage into a cohesive one.

\section{Discussion}

The reported experimental and theoretical results, which describe the characteristics of the Zn-alumina interaction on the same hydroxylated $\alpha-\mathrm{Al}_{2} \mathrm{O}_{3}(0001)$ termination, consistently provide a thorough picture of the conditions under which surface hydroxylation is beneficial to adhesion.

As far as the regime of weak adsorption/adhesion of metallic $\mathrm{Zn}$ on the hydroxylated alumina surface in the absence of $\mathrm{Zn}$ $\mathrm{OH}$ reaction is concerned, the calculated $E_{a d s}$ of $0.23 \mathrm{eV} /$ atom for isolated zinc adatoms is fully consistent with the maximum temperature at which $\mathrm{Zn}$ adatoms can be experimentally stabilized on the alumina surface, i.e. around $220 \mathrm{~K}^{25}$ corresponding to $E_{a d s} \approx 0.4 \mathrm{eV} /$ atom. ${ }^{52}$ At higher $\mathrm{Zn}$ coverage, the computational estimate of $E_{a d h}$ in the

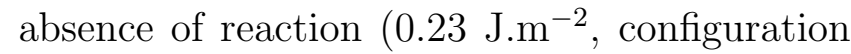
$\mathrm{C}_{2}$ ) is smaller than that derived from SDRS measurements at $100 \mathrm{~K}\left(0.75{\left.\mathrm{~J} . \mathrm{m}^{-2}\right)}^{-2}\right.$ (Table 1$)$ maybe because of kinetic effects. However, 
since all these estimates are lower than the $\mathrm{Zn}$ cleavage energy $\left(1.08 \mathrm{~J} . \mathrm{m}^{-2}\right)$, both experiment and theory demonstrate that in the absence of $\mathrm{Zn}-\mathrm{OH}$ reaction, the $\mathrm{Zn} /$ alumina cleavage is interfacial, no matter whether the surface is hydroxylated or not.

Under conditions such that zinc oxidation takes place, both experimental and theoretical results concur to evidence ionized Zn species strongly bound to the alumina surface. In particular, Zn deposition on a pre-hydroxylated surface, followed by hydrogen desorption, is characterized by a calculated large adsorption energy (configuration $\mathrm{A}_{4}, E_{a d s}=5.14 \mathrm{eV} / \mathrm{Zn}$ atom, Table 2), which is consistent with the estimate of the $\mathrm{Zn}^{2+}$ desorption energy $\left(E_{\text {des }} \simeq\right.$ $3.9 \mathrm{eV} / \mathrm{Zn}$ atom, estimated from the desorption temperature of $1380 \mathrm{~K}$, Tables 1). In addition, in the presence of such strongly bound interfacial oxidized $\mathrm{Zn}$ species and after $\mathrm{H}$ desorption (configuration $\mathrm{B}_{4}$ ), the calculated adhesion energies $\left[1.71 \mathrm{~J} . \mathrm{m}^{-2}\right.$ at $\left(\mathrm{i}_{1}\right)$ and $1.63 \mathrm{~J} . \mathrm{m}^{-2}$ at $\left.\left(\mathrm{i}_{2}\right)\right]$ are both higher than the Zn cleavage energy $\left(1.08 \mathrm{~J} . \mathrm{m}^{-2}\right)$. These theoretical results are confirmed by the experimentally measured increase in the desorption energy of $\mathrm{Zn}^{0}$ in the presence of $\mathrm{Zn}^{2+}$ ionized species.

Interestingly, both theory and experiment agree that an activation is necessary to make the transition between the two regimes absence of $\mathrm{Zn}-\mathrm{OH}$ reaction or formation of strongly bound $\mathrm{Zn}$ species. Theory proposes $(\mathrm{ZnH})^{+}$moiety formation (configuration $\mathrm{B}_{2}$ ) as an intermediate step in this transition, followed by hydrogen desorption that leaves the $\mathrm{Zn}$ ions on the surface. This is supported by the TPD observation of hydrogen desorption at temperatures higher than that at which metallic Zn ends desorbing. Therefore, the oxidation of zinc at the $\mathrm{Zn} /$ alumina interface is not enough to switch from interfacial to cohesive cleavage, but a full removal of hydrogen is also needed, as proven by the link between the Zn chemical state and the hydrogen desorption.

Finally, the cohesive nature of the $\mathrm{Zn} /$ alumina cleavage that results from deposition and reaction on the hydroxylated surface after hydrogen removal can be assigned to the formation of strong O-Zn bonds, between the ionized $\mathrm{Zn}$ atoms and the alumina surface [interface $\left(\mathrm{i}_{1}\right)$ ] and between interfacial oxygen atoms, remnant of the hydroxyl group, and the Zn deposit [interface $\left.\left(i_{2}\right)\right]$. The latter are of mixed ionocovalent character, as revealed by a sizeable charge transfer and, as such, give rise to an adhesion energy much larger than the Zn cleavage energy (1.63 J.m ${ }^{-2}$ versus $1.08 \mathrm{~J} . \mathrm{m}^{-2}$, Table 2). It is to be stressed that no such enhancement of adhesion at $\left(\mathrm{i}_{2}\right)$ exists if a full $\mathrm{ZnO}$ monolayer is formed at the Zn/alumina interface accordingly to simulations ${ }^{42}\left[E_{\text {adh }} \sim 1.4-1.5 \mathrm{~J} \mathrm{~m}^{-2}\right.$ at $\left(\mathrm{i}_{1}\right)$, but only $0.8-1.0 \mathrm{~J} \cdot \mathrm{m}^{-2}$ at $\left.\left(\mathrm{i}_{2}\right)\right]$. The weak adhesion at $\left(\mathrm{i}_{2}\right)$ in this case is due to a higher coordination of interfacial oxygen ions, which makes their bonding with the Zn deposit weaker. This comparison highlights the key role of the under-coordination of interfacial oxygen species, such as those involved in dispersed $\mathrm{ZnO}$ moieties formed on the pre-hydroxylated surface. It shows that an initial surface hydroxylation may conveniently provide the quantity of residual anions which is both necessary and sufficient for the stabilization of a constituted zinc deposit on the alumina surface.

\section{Conclusion}

In summary, by combining experimental and theoretical evidences, we have shown that surface pre-hydroxylation may lead to a dramatic enhancement of zinc adsorption/adhesion. We demonstrate that, while zinc adsorbs very weakly either on $\mathrm{OH}$-free alumina or on hydroxylated alumina in the absence of $\mathrm{Zn}-\mathrm{OH}$ reaction, an activated adsorption on the $\mathrm{OH}-$ covered surface followed by hydrogen desorption produces interfacial oxidized $\mathrm{Zn}$ species and under-coordinated oxygen ions. Most interestingly, the measured and calculated increases of metallic zinc binding in the presence of such oxidized species point unambiguously towards an overall interface strengthening. Computational results rationalize the process and, beyond the expected strong interaction of interfacial ionized $\mathrm{Zn}$ with the alumina surface, they highlight the key role of under- 
coordinated interfacial anions, remnants of the surface hydroxylation layer which are responsible for the switch from interfacial cleavage for $\mathrm{Zn} / \mathrm{OH}$-free alumina to cohesive cleavage for $\mathrm{Zn} /$ hydroxylated alumina. The novelty of the scenario proposed herein is to link the improvement in adhesion to the entire interfacial chemistry between the metallic adlayer and the surface hydroxyl groups. By pinpointing the role played by each species involved in the interface, metal, oxygen and hydrogen, it sets up a general framework to investigate whether hydroxyl groups are prone to enhance the adhesion at any given metal/oxide interface.

Acknowledgement H.-L. T. L. acknowledges a post-doctoral grant from ArcelorMittal Maizières Research, R.C. aknowledges a PhD CIFRE grant from both ArcelorMittal Maizières Research and Agence Nationale de la Recherche et de la Technologie, and the authors thank IDRIS for a generous allocation of computing time, under Project No. 100170. This work was supported by French state funds managed by the ANR within the Investissements d'Avenir programme under reference ANR-11IDEX-0004-02, and more specifically within the framework of the Cluster of Excellence MATISSE led by Sorbonne Universités.

\section{Supporting Information Avail- able}

The following files are available free of charge. Description (S1) of the galvanization context of the study, (S2.1) of the differential reflectivity modeling, (S2.2) of the thermal desorption analysis, (S2.3) of the Zn LMM Auger lineshape, (S2.4) of zinc film thickness determination and (S2.5) of the LEED patterns.

\section{References}

(1) Campbell, C. T. Ultrathin Metal Films and Particles on Oxide Surfaces: Structural, Electronic and Chemisorptive Properties. Surf. Sci. Rep. 1997, 2\%, 1-111.

(2) Fu, Q.; Wagner, T. Interaction of Nanostructured Metal Overlayers with Oxide Surfaces. Surf. Sci. Rep. 2007, 62, 431498.

(3) Bordier, G.; Noguera, C. Electronic Structure of a Metal-Insulator Interface: Towards a Theory of Nonreactive Adhesion. Phys. Rev. B 1991, 44, 6361-6371.

(4) Goniakowski, J.; Noguera, C. Electronic States and Schottky Barrier Height at Metal $/ \mathrm{MgO}(100)$ Interfaces. Interf. Sci. 2004, 12, 93-103.

(5) Lazzari, R.; Jupille, J. Interfacial Chemistry and Wetting of Metallic Films on the Hydroxylated $\alpha-\mathrm{Al}_{2} \mathrm{O}_{3}(0001)$ Surface. Phys. Rev. B 2005, 71, 045409.

(6) Goniakowski, J.; Mottet, C.; Noguera, C. Non-reactive Metal/Oxide Interfaces: From Model Calculations Towards Realistic Simulations. Phys. Stat. Sol. (b) 2006, 243, 2516-2532.

(7) Chambers, S. A.; Droubay, T.; Jennison, D. R.; Mattsson, T. R. Laminar Growth of Ultrathin Metal Films on Metal Oxides: Co on Hydroxylated $\alpha-\mathrm{Al}_{2} \mathrm{O}_{3}(0001)$. Science 2002, 297, 827831.

(8) Cavallotti, R.; Goniakowski, J.; Lazzari, R.; Jupille, J.; Koltsov, A.; Loison, D. Role of Surface Hydroxyl Groups on Zinc Adsorption Characteristics on $\mathrm{Al}_{2} \mathrm{O}_{3}(0001)$ Surfaces: First-Principles Study. J. Phys. Chem. C 2014, 118, 13578-13589.

(9) Coustet, V.; Jupille, J. High-Resolution Electron-Energy-Loss Spectroscopy of Isolated Hydroxyl Groups on 
$\alpha-\mathrm{Al}_{2} \mathrm{O}_{3}(0001) . \quad$ Surf. Sci. 1994, 307-309, 1161-1165.

(10) Coustet, V.; Jupille, J. Hydroxyl Groups on Oxide Surfaces. Il Nuovo Cimento D 1997, 19, 1657-1664.

(11) Elam, J. W.; Nelson, C. E.; Cameron, M. A.; Tolbert, M. A.; George, S. M. Adsorption of $\mathrm{H}_{2} \mathrm{O}$ on a Single-Crystal $\alpha-\mathrm{Al}_{2} \mathrm{O}_{3}(0001)$ Surface. J. Phys. Chem. B 1998, 102, 7008-7015.

(12) Hass, K. C.; Schneider, W. F.; Curioni, A.; Andreoni, W. The Chemistry of Water on Alumina Surfaces: Reaction Dynamics from First Principles. Science 1998, 282, 265-268.

(13) Kelber, J. A.; Niu, C.; Shepherd, K.; Jennison, D. R.; Bogicevic, A. Copper Wetting of $\alpha-\mathrm{Al}_{2} \mathrm{O}_{3}(0001)$ : Theory and Experiment. Surf. Sci. 2000, 446, 76-88.

(14) Niu, C.; Shepherd, K.; Martini, D.; Tong, J.; Kelber, J. A.; Jennison, D. R.; Bogicevic, A. $\mathrm{Cu}$ Interactions with $\alpha-\mathrm{Al}_{2} \mathrm{O}_{3}(0001)$ : Effects of Surface Hydroxyl Groups versus Dehydroxylation by Ar-ion Sputtering. Surf. Sci. 2000, 465, 163-176.

(15) Grässel, O.; Krüger, L.; Frommeyer, G.; Meyer, L. W. High Strength $\mathrm{Fe}-\mathrm{Mn}-(\mathrm{Al}, \mathrm{Si}) \mathrm{TRIP} / \mathrm{TWIP}$ Steels Development - Properties - Application. Int. J. Plast. 2000, 16, 1391-1409.

(16) Jiang, H.-T.; Ding, W.; Tang, D.; Huang, W. Mechanical Property and Microstructural Characterization of $\mathrm{C}-\mathrm{Mn}-\mathrm{Al}-\mathrm{Si}$ Hot Dip Galvanizing TRIP Steel. J. Iron and Steel Research 2012, 19, 29-36.

(17) Nikulin, I.; Sawaguchi, T.; Tsuzaki, K. Effect of Alloying Composition on Low-Cycle Fatigue Properties \& Microstructure of $\mathrm{Fe}-30 \mathrm{Mn}-(6-\mathrm{x}) \mathrm{Si}-\mathrm{xAl}$ TRIP/TWIP Alloys. Materials Science and Engineering A 2013, 587, 192-200.
(18) Wang, W.; Li, M.; He, C.; Wei, X.; Wang, D.; Dub, H. Experimental Study on High Strain Rate Behavior of High Strength 600-1000 MPa Dual Phase Steels and $1200 \mathrm{MPa}$ Fully Martensitic Steels. Materials and Design 2013, 47, 510-521.

(19) Mertens, A.; Bellhouse, E. M.; McDermid, J. R. Microstructure and Mechanical Properties of a Mixed Si - Al TRIPAssisted Steel Subjected to Continuous Galvanizing Heat Treatments. Materials Science \& Engineering A 2014, 608, 249257.

(20) Cavallotti, R. Effets de la Terminaison de l' $\alpha$-Alumine (0001) sur le Comportement au Mouillage du Zinc. Ph.D. thesis, Université Pierre et Marie Curie (UPMC), Paris, France, 2014.

(21) Cavallotti, R.; Le, H.-L. T.; Goniakowski, J.; Lazzari, R.; Jupille, J.; Koltsov, A.; Loison, D. New Routes for Improving Adhesion at Metal $/ \mathrm{Al}_{2} \mathrm{O}_{3}(0001)$ Interface. Phys. Chem. Chem. Phys. 2016, 18, 3032-3039.

(22) Lazzari, R.; Jupille, J.; Cavallotti, R.; Simonsen, I. Model-Free Unraveling of Supported Nanoparticles Plasmon Resonance Modes. J. Phys. Chem C 2014, 118, 7032-7048.

(23) Lazzari, R.; Jupille, J. Chemical Reaction via Hydroxyl Groups at the $\mathrm{Ti} / \alpha-\mathrm{Al}_{2} \mathrm{O}_{3}$ Interface. Surf. Sci. 2002, 507-510, 683687.

(24) Renaud, G.; Villette, B.; Vilfan, I.; Bourret, A. Atomic structure of the $\alpha-\mathrm{Al}_{2} \mathrm{O}_{3}(0001)(\sqrt{31} \times \sqrt{31}) R \pm 9^{\circ}$ reconstruction. Phys. Rev. Lett. 1994, 73, 1825-1828.

(25) Rodriguez, J. A.; Kuhn, M.; Hrbek, J. Interaction of Silver, Cesium, and Zinc with Alumina Surfaces: Thermal Desorption and Photoemission Studies. J. Phys. Chem. 1996, 100, 18240-18248. 
(26) Simonsen, I.; Lazzari, R.; Jupille, J.; Roux, S. Optical Response of Supported Particles. Phys. Rev. B 2000, 61, 77227733.

(27) Lazzari, R.; Simonsen, I.; Bedeaux, D.; Vlieger, J.; Jupille, J. Polarizability of Truncated Spheroidal Island Supported by a Substrate: Models and Applications. Eur. Phys. J. B 2001, 24, 267-284.

(28) Lazzari, R.; Roux, S.; Simonsen, I.; Jupille, J.; Bedeaux, D.; Vlieger, J. Multipolar Plasmon Resonances in Supported Silver Particles: the Case of $\mathrm{Ag} / \alpha-\mathrm{Al}_{2} \mathrm{O}_{3}(0001)$. Phys. Rev. B 2002, 65, 235424-1-13.

(29) Lazzari, R.; Simonsen, I. GranFilm: a Software for Calculating Thin Layer Dielectric Properties and Fresnel Coefficients. Thin Solid Films 2002, 419, 124136.

(30) Lazzari, R.; Jupille, J. Growth Kinetics and Size-dependent Wetting of $\mathrm{Ag} / \alpha$ $\mathrm{Al}_{2} \mathrm{O}_{3}(0001)$ Nanoparticles Studied via the Plasmonic Response. Nanotechnology 2012, 23, 135707.

(31) GranFilm can be downloaded with an user guide from: http://www.insp.jussieu.fr/Logiciels-.html.

(32) E. Habenschaden, J. K. Evaluation of Flash Desorption Spectra. Surf. Sci. 1984, 138, L147-L150.

(33) Wöll, C. The Chemistry and Physics of Zinc Oxide Surfaces. Prog. Surf. Sci. 2007, 82, 55-120.

(34) NIST Standard Reference Database 20, Version 4.1 (https://srdata.nist.gov/xps/Default.aspx), 2012 .

(35) Kresse, G.; Furthmuller, J. Efficient Iterative Schemes for $a b$ initio Total Energy Calculations Using a Plane-Wave Basis Set. Phys. Rev. B 1996, 54, 11169 11186.
(36) Kresse, G.; Hafner, J. Ab initio Molecular Dynamics for Liquid Metals. Phys. Rev. B 1993, 47, 558-561.

(37) Blöchl, P. E. Projector Augmented-Wave Method. Phys. Rev. B 1994, 50, 1795317979 .

(38) Kresse, G.; Joubert, J. From Ultrasoft Pseudopotentials to the Projector Augmented-Wave Method. Phys. Rev. B 1999, 59, 1758-1775.

(39) Dion, M.; Rydberg, H.; Schroder, E.; Langreth, D. C.; Lundqvist, B. I. Van der Waals Density Functional for General Geometries. Phys. Rev. Lett. 2004, 92, 246401-1-4.

(40) Klimes, J.; Bowler, D. R.; Michaelides, A. Chemical Accuracy for the van der Waals Density Functional. J. Phys.: Cond. Matt. 2010, 22, 022201-1-5.

(41) Klimes, J.; Bowler, D. R.; Michaelides, A. Van der Waals Density Functionals Applied to Solids. Phys. Rev. B 2011, 83, 195131-1-13.

(42) Le, H.-L.; Goniakowski, J.; Noguera, C.; Koltsov, A.; Mataigne, J.-M. FirstPrinciples Study on the Effect of Pure and Oxidized Transition-Metal Buffers on Adhesion at the Alumina/Zinc Interface. $J$. Phys. Chem. C 2016, 120, 9836-9844.

(43) Henkelman, G.; Uberuaga, B.; Jonsson, H. A Climbing Image Nudged Elastic Band Method for Finding Saddle Points and Minimum Energy Paths. J. Chem. Phys. 2000, 113, 9901-9904.

(44) Bader, R. F. W. A Quantum Theory of Molecular Structure and its Applications. Chem. Rev. 1991, 91, 893-928.

(45) Henkelman, G.; Arnaldsson, A.; Jonsson, H. A Fast and Robust Algorithm for Bader Decomposition of Charge Density. Comput. Mater. Sci. 2006, 36, 354-360. 
(46) Momma, K.; Izumi, F. VESTA 3 for Three-dimensional Visualization of Crystal, Volumetric and Morphology Data. J. Appl. Crystallogr. 2011, 41, 1272-1276.

(47) Ahn, J.; Rabalais, J. W. Composition and structure of the $\mathrm{Al}_{2} \mathrm{O}_{3}(0001)(1 \times 1)$ Surface. Surf. Sci. 1997, 388, 121-131.

(48) Lodziana, Z.; Nørskov, J. K.; Stoltze, P. The stability of the hydroxylated (0001) surface of $\alpha-\mathrm{Al}_{2} \mathrm{O}_{3}$. J. Chem. Phys 2003, $118,11179-11188$.

(49) VanCampen, D.; Hrbek, J. Silver on Alumina: Adsorption and Desorption Study Model. J. Phys. Chem. 1995, 99, 1638916394.

(50) Schön, G. Auger and Direct Electron Spectra in X-ray Photoelectron Studies of Zinc, Zinc Oxide, Gallium and Gallium Oxide. J. Electron. Spectrosc. Rel. Phenom. 1973, 2, 75-86.

(51) Fox, J.; Nuttall, J.; Gallon, T. Solid State Effects in the Auger Spectrum of Zinc and Oxidised Zinc. Surf. Sci. 1977, 63, 390402.

(52) Redhead, P. Thermal Desorption of Gases. Vacuum 1962, 12, 203-211. 


\section{Graphical TOC Entry}

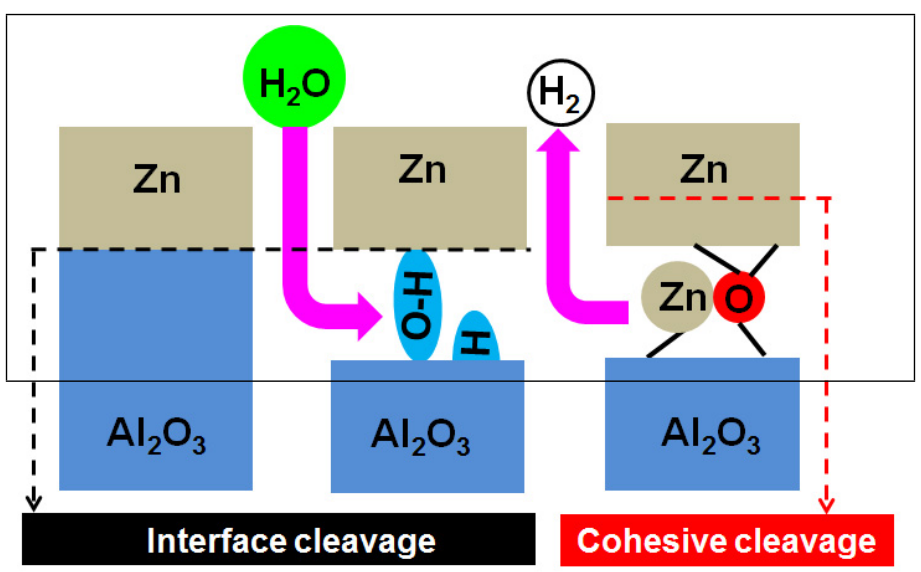

